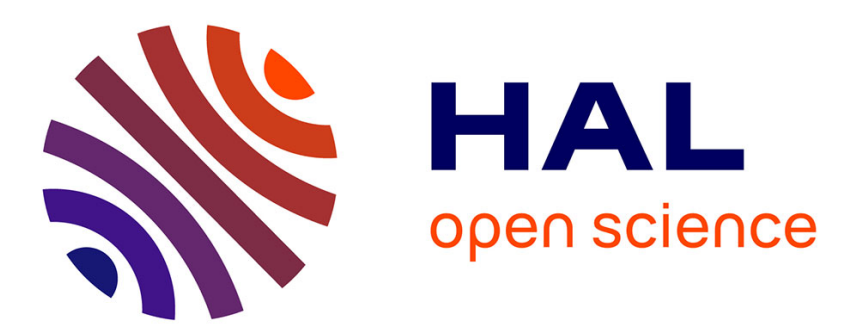

\title{
From how consumers categorize natural food to their buying methods: a comparative study between France and Israel
}

Louis Mathiot

\section{- To cite this version:}

Louis Mathiot. From how consumers categorize natural food to their buying methods: a comparative study between France and Israel. Review of Agricultural, Food and Environmental Studies, 2018, 99 (1), pp.57-76. 10.1007/s41130-017-0056-3 . hal-03114747

\section{HAL Id: hal-03114747 \\ https://hal.science/hal-03114747}

Submitted on 19 Jan 2021

HAL is a multi-disciplinary open access archive for the deposit and dissemination of scientific research documents, whether they are published or not. The documents may come from teaching and research institutions in France or abroad, or from public or private research centers.
L'archive ouverte pluridisciplinaire HAL, est destinée au dépôt et à la diffusion de documents scientifiques de niveau recherche, publiés ou non, émanant des établissements d'enseignement et de recherche français ou étrangers, des laboratoires publics ou privés. 


\title{
From how consumers categorize natural food to their buying methods: a comparative study between France and Israel
}

\author{
Louis Mathiot ${ }^{1}$ (D)
}

Received: 3 October 2016 / Accepted: 30 November 2017 / Published online: 12 December 2017 (C) INRA and Springer-Verlag France SAS, part of Springer Nature 2017

\begin{abstract}
Based on a qualitative investigation comparing the ways in which French and Israeli "ordinary" consumers view naturalness in food, this paper questions the choices they make in terms of food supply and their relations to the food production processes and the retail channels. The results of the study highlight that these representations, with the categorizations in which they are embodied, are strongly influenced by the context of life and the socio-cultural affiliations of these consumers. The comparison between the two countries allows to underline that the logics of categorization of the natural, and the related practices, are characterized by significant differences due to food cultures and relations of trust or mistrust regarding the food chains and industries. More broadly, the article demonstrates that investigating the conceptions that consumers have of naturalness is a relevant analyzer of their dietary decisions and their perceptions of food production and distribution systems.
\end{abstract}

Keywords Sociology $\cdot$ Food $\cdot$ Consumption $\cdot$ Natural $\cdot$ Food sourcing/provisioning

\section{Introduction}

This article focuses on the relationship consumers maintain with food sourcing, based on their conception of naturalness in food. The notion of what is natural is used as an entry point to question eaters' views about food production processes and their marketing and distribution channels as well as the choices they make when buying food supplies for the home. Research focusing on food consumption as part of special dietary regimens has shown the close link made by eaters between the idea of

Louis Mathiot

1mathiot@parisnanterre.fr

1 Centre de Recherche Education Formation (CREF - EA1589), Université Paris Nanterre, 200, Avenue de la République, 92000 Nanterre, France 
naturalness and their eating practices (Ossipow 1997; Ouedraogo 1998; César 1999). It demonstrates how their choices between different retail outlets are based on the guarantees of naturalness offered by alternative and specialized food producers, while the appreciation of naturalness may vary according to a whole set of criteria based on the size of the production/marketing channels, farming methods and conditions of production, or a respect for seasonality. For consumers who do not subscribe to these particular food requirements, the question of naturalness in food has become increasingly important over the past two decades. This can be measured by the dietary guidelines and marketing discourse addressed to them (Lepiller 2012a) as well as by their eating patterns, which involve greater reflexivity about the ways food is produced, in a concern to respect its naturalness (Wier et al. 2003; Lamine 2007; Roininen et al. 2006). No specific study has yet been made which would cast light on the concept of what is natural from the viewpoint of these eaters - the way they envisage naturalness and adapt their shopping accordingly — and this is the focus of our research. In studying this relationship, I shall show how decisions about food are made by French and Israeli consumers, based on not only what for them constitutes naturalness in food but also what is the opposite of it.

The population studied is made up of those I shall here refer to as "ordinary eaters." Far from being a homogenous category, it brings together all those who do not claim to have "personal dietary requirements" (Fischler 2015). These eaters come from a variety of social backgrounds and their food-shopping habits do not tend towards exclusivity in their choice of producers - the buying processes may be eclectic among individuals, who opt as much for conventional as for alternative producers. Although their everyday diet does not involve practices of "ethical consumerism" (Dubuisson-Quellier 2013), taking precautions of a dietary, health, ethical, or environmental nature is not absent from the choices they enact and the judgments they make. Their attitudes towards consumption are obviously part of the tendency to moralize food that is currently being experienced in Western societies - the practices espoused by this trend being prone to intensify discourses relating to self-governance (Coveney 2006).

The fieldwork was based on data gathered as part of an international comparison between France and Israel ${ }^{1}$ - the advantage of this comparison being that the two countries presented both similarities and differences which were instructive for research into food consumption. What they had in common was their agro-industrial type of production systems, their level of economic development, and, last but not least, shared features in their food models (structuring of daily meal times, table behavior, and a shared repertory of certain commonly eaten products). The differences opposing the two countries were their very distinct climates and production environments, which in practice resulted in different relationships between humans and their natural

\footnotetext{
${ }^{1}$ Postdoctoral research funded by the Observatoire CNIEL des Habitudes Alimentaires (OCHA) and conducted in partnership with the Dynamiques Européennes laboratory (DynamE-UMR 7236) entitled "Représentations et mises en pratique de la naturalité en matière d'alimentation: du concept à ses multiples déclinaisons. Étude comparée à l'international." [Perspectives and practice of natural eating: from the concept to its multiple variants. Comparative international study.] This research benefited from a 2-year funding and was conducted between June 2013 and May 2015 under the supervision of Véronique Pardo (OCHA) and Nicoletta Diasio (DynamE). The aim of the research was to understand how categories of foodstuffs associated by consumers with naturalness were produced and to study their links with the way consumers bought, preserved, and stored food.
} 
environment. The size of the territories, as well as their economic and political relationships with neighboring countries, also presented marked differences. Finally, the strong and omnipresent influence of religion in Israel, both in the food on offer and in the organization of certain modes of consumption, distinguished it from France, where religious influence is weak and more present in terms of cultural heritage. These similarities and differences will be dealt with throughout this article and, in some cases, analyzed to show how the association between naturalness and food shows a certain number of constants among the people studied; while at the same time, variations can be seen in the processes by which they categorize natural food and the relationship this has to methods of food buying-processes which are socially, culturally, and geographically embedded.

The research is based on a qualitative type of survey conducted through semistructured interviews with "ordinary eaters." The first phase of the survey was conducted in France in $2014(N=26)$ and the second in Israel in $2015(N=15)$. Since Israel was previously a little-known country, an immersion period of 2 months was added to enable me to understand its food model. The population studied was made up solely of Israeli Jews residing in urban areas, and most of my interlocutors described themselves as hilonim, or secular Jews. The remainder of my respondents called themselves massortim (practicing Jews who observed tradition and Jewish law but whose commitment was not as great as that of the orthodox and ultra-orthodox). A homogenous population was chosen in Israel, with a view to gaining the best possible knowledge of a particular type of population in the time allowed for the survey, and also to avoid dealing with multiple, disparate data; this would have been interesting from a monographic point of view but would make comparison with France difficult.

Detailed research methodology

French territory

The qualitative survey in France was conducted over three types of areas so as to bring out the contrasts between urban and rural environments. Three geographical areas were chosen for the French study: a metropolis represented by the national capital (Paris), a large city with a departmental prefecture (Nancy in Lorraine), and rural communes (in Lorraine) of under 2000 inhabitants, situated beyond a town's sphere of influence (cf: INSEE nomenclature).

Nine interviews were in Paris, eight in Nancy, and nine in rural areas. The proportion of women to men was equal and the respondents were uniformly divided between three types of social background (working, middle, and privileged classes) so that it would be a meaningful criterion when analyzed.
Israeli territory

To avoid increasing the points of comparison, the qualitative survey in Israel was limited to urban environments. Two types of areas were singled out: metropolitan areas that were important economic and cultural centers (Tel Aviv and Jerusalem) and mid-sized urban areas comprising three towns with populations of between 80,000 and 200,000 inhabitants (Rehovot, Herzliya, and Ashdod). Nine interviews were conducted in the metropolitan areas and six in the mid-sized urban areas.

The proportion of women to men was equal and the respondents were from the middle or privileged classes of the population. This last factor was taken into account when analyzing the data.

Following a brief review of the existing social science research dealing with the subject of natural foods, this article aims to question the general views of eaters on what is natural and to understand the logic by which "ordinary eaters" class a food as natural. This will be based on the following questions: what types of foods are associated with naturalness? What elements are perceived as strong indicators of naturalness? Are these 
more related to the result of human intervention or to pre-existing food categories? In both cases, how are the values accorded to foods graded so that some are closer to the "natural" end of the spectrum and others further away or even at the opposite end? These perceptions will be looked at with respect to the eaters' shopping practices but also, more broadly, examined with respect to their relationship with the different foodsourcing possibilities.

\section{How natural food became a theme}

In social sciences over the past 20 years, research into what is natural when associated with food has been based on two main lines of study. The first has produced a body of reasoned argument around naturalness in relation to the food industries. The second focuses on eaters' points of view and how the concept of what is natural has come to underpin a whole category of foods which for them constitute a "culinary system" (Douglas 1979).

\section{Naturalized products in the food industry}

The food industry, referring to all systems for producing and processing food, has contributed substantially to placing value on the natural aspect. In French marketing discourse, natural would seem to signify that a food contains no external elements considered to be "artificial," such as additives ${ }^{2}$ or ingredients thought to be separate from the basic composition of the product or dish being marketed. As Olivier Lepiller's (2012a) recent work has shown, this "naturalization" drive dates back to the 1960s. From analysis carried out on a corpus of articles (in the press and in scientific publications) and on campaigns and publicity strategies by the food industries, a typology has been produced of the naturalization efforts undertaken by industrialists, together with a typology of criticism of industrial food. The thesis shows how criticism spread and was gradually "digested" by the food industry. This process of endogenization took place over three main periods: from 1960 to 1970 when criticism grew; from 1970 to the mid-1990s, when criticism was domesticated by the foodprocessing industry; and the late 1990 s to 2010 , when this criticism was re-appropriated by industrialists who promoted their products' natural features while, at the same time, criticism of them was being renewed with increased vigor. It was during this latter period that a rhetoric extolling the natural could be heard in the discourse put out by the food-processing industry. This attempt to improve their products' status was based mainly on a discourse aiming to "naturalize" a series of manufactured food products (Lepiller 2012b) and not on a thoroughgoing change in the processes for producing/processing these products.

\section{Natural food from the eaters' point of view}

As for eaters, research has focused mainly on the views that those committed to eating special diets hold with regard to what is natural in their food, and how these views are

\footnotetext{
${ }^{2}$ As products added to commercial foodstuffs, additives are generally associated with the artificial element of a product. They come in a variety of forms such as preservatives, sweeteners, gelling agents, colourings, flavor enhancers, stabilizers, etc. They are classified according to an Exxx or Exxxx system.
} 
rooted in daily practice. Both quantitative (Ouedraogo 1998) and qualitative studies (César 1999) have been conducted, particularly of consumers who eat only organic products. Christine César's work has been able to establish how the nature/food association is built up from binary oppositions identified in these eaters' discourses. We find a whole range of terms set in opposition to one another, starting from the source dichotomy which constitutes a value concept: the natural on the one hand, and the artifact on the other. Without giving an exhaustive list, the pairs of oppositions are the following: organic/chemical, additive-free/with additives, healthy/unhealthy, authentic/artificial, traditional/ modern, living/dead.

At an intermediate level between eaters committed to special diets and "ordinary eaters," Claire Lamine has compared "organic purists" with "intermittent organic eaters" (2007). Characteristic of the latter were eating practices that sometimes tended towards organic products and at others towards products from conventional sources. The intermittent character was not restricted only to categories of products but also included times and places of food consumption. Occurrences of the terms "nature" and "natural" in the discourses collected were subjected to analysis, thus allowing the eaters' ideas to emerge and their eating trends to be interpreted on the basis of this entry.

Other research has not focused directly on the natural object itself, but studied it in a roundabout way from discourse produced by eaters following special diets; naturalness had a strong resonance in their discourses when it came to understanding the meaning they gave to their choices. We might quote the work of Laurence Ossipow (1997), who has made a special study of vegetarians, vegans, and macrobiotics. More recently, the work of Camille Adamiec (2016), studying those who place great importance on "eating healthily" in their daily lives, also contributes a whole catalog of information about the way eaters conceive naturalness.

\section{The "natural" entry in food: methodological precautions}

Knowledge of the forms of classifying naturalness as produced by the food industries and those committed to special diets provides important benchmarks for questioning the categorizations of "ordinary eaters" in their turn. However, this knowledge may create a bias in survey situations with ordinary eaters, and therefore calls for methodological precautions.

The main precaution consists in not substituting the meaning of natural as developed by the food industry for the meaning envisaged by consumers. From alternative diets to specialized segments in "natural products," by way of major brands that promote the naturalness of their products through the absence of artificial additives, the increased prestige of the natural has multiple categories (Lepiller 2010) within it, and one has to be careful not to suggest them. The same logic dictates that it is equally important not to attribute the characteristics of naturalness seen by eaters committed to a special diet to those of "ordinary eaters," because they are not always transferable. The works previously cited show how the process of naturalizing eating practices can extend to more general values concerning the relationship to the body and personal hygiene, or even to forms of "magical eating" (Fischler 1994). For example, studies of 
eaters who exclude meat from their diet and of those who favor biodynamic farming show the close links made between naturalness and food based on specific notions such as the "vital cosmic link" (Ossipow 1997). These references generally have no meaning for ordinary eaters who, as we shall see, judge what is natural from other standpoints.

So as to avoid suggesting to respondents what might be associated with naturalness in food, a series of precautions were taken to allow their ideas to emerge spontaneously. At the start of the interview, the questions were oriented towards their eating styles, the values they prioritized in the way they shopped and whether these values diverged from what they considered to be ideal food (noting in passing what constituted this ideal). In some cases, an explicit reference to the idea of naturalness was brought up spontaneously and then became the springboard for more precise comments; when this was not the case, we asked how they associated the idea of naturalness with food, explaining that our study was particularly interested in the variety of associations produced by individuals and not in a narrow view which they had to respond to.

\section{Comparing food models to reconstruct categories}

A comparative psychological study on the preference for naturalness in food has already been conducted by Paul Rozin among "ordinary eaters" in the USA and five European countries, including France (2008). The survey showed that the perception of naturalness in food varied significantly between the countries, particularly between the USA and the others. Nevertheless, the difference emerged from a shared conception of naturalness, namely the addition or removal of an element in the product's composition.

The framework chosen for our analysis offers new perspectives for studying eaters' views because it forms part of a quest to "compare the incomparable" (Detienne 2000) between two food models which differ markedly in their systems for classifying what is eatable or uneatable. Mary Douglas showed in this context how dietary restrictions in Judaism were deeply rooted in the culture and its taxonomy of pure and impure 1966) rather than in a process of adaptation espoused by supporters of cultural materialism (Harris 1985). On the French side, the shared repertory of what was eatable was based on another cultural model whose roots are partly connected to the development of a culinary tradition defining itself as particularly elaborate and refined. These are obviously not the only factors underlying the dietary models of these two countries, but they show how these models rest on distinct heritages; and, as we shall see, they were widely reused and even reinterpreted by our respondents to present what, in their view, the natural aspect of food was based upon. Comparing what is distant thus makes it possible not only to identify different cultural logics but also to apprehend common, if not similar social undercurrents (Detienne 2000), which will also be awarded particular attention here.

The subject of this study therefore fits within comparative sociology, the aim being to "explore new, unexpected directions" (de Verdalle et al. 2012: 10) and to understand how categories of naturalness are constructed, based on the two countries examined. In order to achieve this, great vigilance has been shown in 
translating the lexical fields relating to the different themes of our subject, between the languages used in each country ${ }^{3}$ - this concern was all the more important since notions and concepts formed the "compass" of our comparison (Dogan and Pélassy 1982). The two procedures for collecting empirical data were also thought out beforehand in order to be able to compare the various data. So as to "construct the comparable" (de Verdalle et al. 2012: 16), we therefore used two systems of enquiry which were not exactly symmetrical. ${ }^{4}$ Moreover, since the timing and conditions of access were not identical for both countries, the choice of focusing on an urban population in Israel, belonging to the intermediate and privileged social categories, was taken with the concern to build up a homogeneous corpus which would be comparable to the one gathered in France (of which a substantial part covered similar characteristics). The analysis categories on the Israeli side cannot therefore be generalized for the whole of the population because they correspond to the urbanized middle class segment.

\section{Common perceptions of what is natural with respect to food}

In both France and Israel, "ordinary eaters" produced associations between naturalness and food that shed light on different categorization processes. There was, however, a view shared by all of the population studied, namely of food perceived as the opposite of natural.

\section{Respondents' shared perceptions about food being the opposite of natural}

The first observation regarding what is opposite to natural, from the viewpoint of ordinary eaters, and contrary to those who support exclusively organic food, is that "artifacts" 5 do not necessarily denaturalize a food product. The addition of certain synthetic substances or additives is not thought to taint the food; some respondents even explained that there was no such thing as an artifact insofar as it was a natural byproduct:

Jérôme: [everything] comes from nature. Take the case of medicine, for example - a medicine is always based on a natural molecule. It's rare for something to be created by humans. Obviously, you dig into the databank you have of what's natural, and then you tinker around with all that to get a med that works. But the

\footnotetext{
${ }^{3}$ The interviews were conducted in English in Israel but there were a few interviews in French with Israelis who could speak that language. During the exploratory study, a whole terminology relating to nature and food was translated so as to gain familiarity with equivalent terms and possible nuances between Hebrew, English, and French.

${ }^{4}$ Many participating observations of meals were made in Israel, whereas this was not the case in France. Moreover, the guide intended for interviews with Israelis included themes with an exploratory purpose, which did not figure in the one used with French respondents. This enabled little-known information to be collected for Israel, whereas we already knew about France because of previous research on related subjects (see Mathiot 2014).

${ }^{5}$ The artifact is understood here in the sense given to it by Christine César (1999), that is to say an artificial element produced by humans and their technologies which, once added to basic foodstuffs, denaturalize them.
} 
main element is nature. Even an antidote based on snake venom. The idea comes from nature because all you're doing is copying and pasting. (Interview with Jérôme, associate profession and technical occupation, Nancy)

Unlike certain views shared by eaters committed to special diets, who see naturalness as closely linked with "human non-intervention"6 - as part of a natural/artificial dichotomy and its variants, presented earlier - these consumers' ways of thinking and categorizing are based more on a bipolar system with, at one extreme, food that is always linked to its original environment and, at the other, a product that has gone through the agro-industrial chain and, consequently, become "de-socialized" (Poulain 2002).

Interviewer: for you, what product would be the opposite of natural?

Gaël: perhaps ready-made meals, because in fact they're not very good. That's right... well, I've rarely seen ready-made dishes like those served for lunch, things already prepared that were really not good. Like the texture, the fact that... Even the sauce isn't good, it's really sad. I used to eat a lot of them when I was at [former job], lunch dishes, I mean, to begin with, when I started. And, frankly, it wasn't expensive to eat lunch, that's why I ate them. But it was really... Despite all their efforts they don't work [...] Besides, there are all sorts of by-products of the food-processing industry, everything that doesn't... that no longer chimes with what's real. I'd put all the food-processing substitutes that exist, all the Kiri, the Vache qui rit [cheese brands], all those things... (Interview with Gaël, management level, Paris)

What automatically sprang to mind for our respondent when we mentioned the opposite of natural were products that had been modified by the food-processing industry. The use of the terms "substitutes" and "by-products" to indicate that these foods come close to the idea of unidentified consumable items (UCOs), in other words foods for which consumers know neither the provenance nor their composition, still less the way in which they have been processed (Fischler 1990).

The opposite of natural is therefore food that no longer has meaning, which is reduced to its functional or marketing aspects. This was also the case when, in Israel, respondents cited the hummus sold in the market (souk) as the archetype of a natural product. In France, home-cooked beef bourguignon and ratatouille could also be placed within the bounds of the natural, even if these dishes contain some ingredients judged artificial out of hand from the viewpoint of "bio-purists."

The preservation of meaning is therefore not exclusively linked to a food's degree of processing by human techniques. Some processes, sometimes even complex ones leading to profound changes in the food's very nature, can preserve meaning if they are perceived to be "traditional." Conversely, this meaning may be questioned or even lost if a food has undergone very slight human intervention. For all our respondents in

\footnotetext{
${ }^{6}$ A view found, for example, among consumers eating exclusively organic products (Ouedraogo 1998; César 1999).
} 
both countries, there was therefore a consistency around whether foods tend towards being natural or towards the opposite. This constancy has to do with the food's integrity.

\section{Naturalness or respect for food integrity}

Dairy products represent a particularly interesting category for investigating the process of association between food and nature. They were thought of by our respondents as products which are necessarily linked to human intervention, whose manufacturing processes are known and were often even mentioned in interviews: pasteurization for milk, separation of cream from milk and then churning to make butter, the use of fermenting agents to make yoghourt, and the use of penicillin with cheese to produce bloomy rinds or blue veins. Having recourse to modern techniques or the action of an external agent was not thought to denaturalize the product. Our respondents considered such foods to be extremely natural as long as, in their imagination, they were not associated with industrial forms of production. In their opinion, Kiri, Babybel, and other cheeses were directly opposite because the very nature of cheese was not respected: they were perceived-as Gaël recalled in his interview extract —as an industrial concoction obtained by processes that destroyed the basic food.

There was a strong sense of food being denaturalized when it goes through the agroindustrial chain. However, this does not make it unfit for consumption. As many admitted, they also ate anything that was the opposite of natural food, but these foods came very low down on the scale of "respectability." For Anna, an Israeli student living in Rehovot, the opposite of natural is "anything put in a packet, whose identity you don't really know." As a typical example, she mentions Bambas, a peanut snack (marketed by Curly in France) and all other snack-type foods, which she thinks Israelis eat too much of between meals. She herself says she likes Bambas but eats them sparingly because they are considered to be "pure industrial products" and consequently bad for health.

Foods that remain natural are those of which the integrity has been preserved as they are produced. Integrity can be maintained at different levels of human intervention. On the one hand are interventions that accept "domestic naturalization" techniques that is to say when spontaneous metamorphosis comes to be "managed by technology" (Lepiller 2012a). This is the case with cheese, but also with other foods that require fermentation, such as wine or bread, on the grounds that they "belong to a tradition, they have been tried and tested over time and have become familiar as a result" (Lepiller 2016: 75). In the view of some consumers, on the other hand, this rationale extends even to foods that may allow the use of farming techniques or the addition of substances condemned by "bio-purists" (Lamine 2007). The reasonable use of pesticides for some French consumers or genetic engineering for some Israelis do not necessarily debase the natural aspect of the food. Integrity is maintained as long as the food has not been severed from its "natural environment."

This severance is perceived as originating in the food-processing industry's practice of breaking down a food's original composition, causing it to lose its link with the environment from which it is supposed to have come. The separation between the food and its natural origin may also be seen to arise from farming methods when these use processes that defy the laws of nature and go against them. This is how some basic 
foodstuffs lose their integrity even though they have not been broken down (like those mentioned previously), but because processes have been used that are deemed to be "against nature."

Interviewer: And what, for you, is the opposite of natural?

Jérôme: You see, for example, bone meal, now that's typical of intensive agriculture. It's utter madness because they've made cows eat cows. It's really incredible. It goes against nature because they've managed to make vegetarian animals eat meat. And even eat their fellow creatures. So that's going completely against nature! It's nonsense. And it's still going on, even when they're made to eat grain. A cow doesn't eat grain. It eats hay or grass. It's perhaps not as bad, if I can say that, but it's still not natural. A cow is [meant to be] in a pasture, grazing, it eats forage in winter but it doesn't eat grain.

Interviewer: So is foie gras made on a farm where force-feeding is being practised according to the rules still natural?

Jérôme: Well, it's still natural given that, in any case, they are migratory birds that force-feed themselves before they migrate. So, if they are force-fed more than they force-feed themselves naturally... (Interview with Jérôme, associate profession and technical occupation, Nancy)

Noëlie Vialles's study shows that the discovery of BSE was interpreted as a "denaturalization" of beef due to "carnivorism" or even "cannibalism," "the disease appearing to be a sign or proof of the transgressive nature of these denaturalizations" (2007). Interpreting a practice as going against nature is what causes a food's loss of integrity, and consequently its natural aspect. Although this logic was common to all the people studied, the extent to which the interpretation set limits with regard to working with nature or going against it varied according to the groups. What emerged generally was that it is possible to assist what is produced by nature if its categorization principles are not infringed - principles established by human observation of the modes of rearing and feeding different species. While, for Jérôme, force-feeding a duck did not constitute a transgression (because he found a natural justification linked to his food culture); he considered genetic engineering in agriculture to be going against nature. On the other hand, Oded, ${ }^{7}$ an Israeli respondent, thinks that making an animal overeat goes against nature, of which the principles are theoretically that humans respect animal life — but, from his point of view, the fact that they genetically engineer species remains within the scope of assisting nature.

When consumers think about and describe natural food, it triggers a whole process of reflection on what is upstream of eating habits. Natural objects form a particularly interesting entry point in this regard, to investigate the ways they perceive methods of food production and marketing. What all the discourses agree on in their idea of what is natural is the fact that food preserves a sort of integrity, and the opposite of natural is referred to as "industrial." All the "ordinary eaters" characterize "industrial food" as

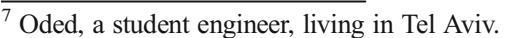


any food whose consumption is disconnected from its production methods. However, behind the commonly used generic term of "industrial," there are multiple interpretations depending on who is being interviewed, as well as a precise definition of where agro-industrial intervention begins.

\section{Different representations of natural food according to eaters' social and cultural backgrounds}

With regard to the term "nature," Paul Arnould and Eric Glon write that "it is overburdened with perceptions, representations and connotations which mean that what is nature for some is never really the same for others, that yesterday's nature is not always the same as today's and that nature here has little to do with nature elsewhere" (2006: 227). This has indeed been the case in our survey of France and Israel. The logic of categorization diverges on several levels: first, on the level of the food cultures in each country, and second on the social level within the same country, which we shall analyze in the case of France (since, in the Israeli survey, we were unable to make a comparison between different social categories).

Furthermore, it would appear that this taxonomy offers an abundance of elements relating to people's representations regarding means of food sourcing. We should, however, avoid falling into the trap of considering these perceptions as determining food-sourcing practices. On the other hand, studying them enables us to analyze the relationship which eaters have with food supply channels and, in particular, the confidence they place in them.

\section{French categorization of natural products seen through the lens of food processing}

For the French respondents, what mainly governed the logic they used to classify natural food and distinguished them from the Israelis was the practice of food processing and the idea that the less food was altered by human activity the more natural it was. The concept of a denaturalizing process was nevertheless subject to variation, affecting some social classes more than others. Following the analysis of data collected in the field, three main categories emerged. The first, borrowed from Claire Lamine, was characterized by a "non-intervention" link (2007), which was here readapted for our respondents by the concern for reduced human intervention. More evident in the second was regard for a low level of manufacturing in food. The last related to a critical view of naturalness, expressing the fact that this category now no longer exists. Other associations with the idea of "tradition" then appeared to reaffirm this link considered as lost.

Natural food characterized by a non-intervention link This is food that has been the least transformed by humans. For these eaters, it does not of course mean food acquired by hunting or gathering, or that has not undergone the domestic process of selection and crossbreeding of species from Neolithic times up to the present day. However, a food's degree of integrity is high enough for it to remain natural and this implies that vegetables, legumes, oilseeds, meats, and animal by-products have not been substantially modified genetically. The other aspect that is also very important to preserve the 
food from any denaturalization is the fact that its composition has not been affected by external processes using chemical or synthetic components in the farming and rearing methods.

The retail outlets mentioned by these eaters as guaranteeing food purity are mainly consumer segments labeled as "organic" in conventional shops (including supermarkets) and alternative shops specializing in organic products. ${ }^{8}$ Other sources of supply in France, such as the Association for Maintaining Small-Scale Family Farming, networks for buying directly from local producers (for example la Ruche qui dit oui, a web tool for accessing organic food) or, indeed, organic market gardeners, who sell their produce directly from markets, are all situated within the perimeter of the non-intervention link (Dubuisson-Quellier 2013). Some respondents who supported this position and lived in rural areas also had access to groups that clubbed together to buy animals or halfanimals (particularly cattle) directly from a breeder who adhered to organic farming practices. The animal was carved up on the spot then divided between the various buyers, who generally belonged to the same network of acquaintances.

The organic label was not considered as the only guarantee of reliability as to the product's purity. Some eaters were critical of organic products from conventional shops, particularly supermarkets. Furthermore, the proximity between vendor and buyer or even the shorter supply chain (in terms of numbers of middlemen) could be subject to doubt, or even suspicion. "Buying from the old local guy, no, I don't trust him. Because the old man probably uses loads of pesticides" Virginie tells us (associate profession and technical occupation in Nancy). "The market, yes, but it depends who from. Because in the Paris markets there are loads of pseudo-greengrocers who get their supplies directly from Rungis [the main Paris wholesale market]," explains Camille (managerial post in Paris). Food naturalness can therefore be ranked according to the supply chain from which it comes.

The archetype of natural food, where there is no knowledge of the farming or rearing methods, is the organic product — one which, when designed to be marketed, is ideally the result of environmentally friendly processes in terms of geographical proximity, a short supply chain, seasonality, and limited or even no packaging. This view was mainly held by those belonging to the more privileged or middle classes of society, generally well-endowed culturally but not necessarily economically (Grignon and Grignon 1981).

Natural food characterized by a "non-manufacturing link" These are foods considered to be "unrefined," which have undergone no culinary transformation beforehand. This applies to fresh foods, even if they have resulted from farming or rearing methods that allow the use of chemical and synthetic components (such as antibiotics for meat and pesticides for vegetables). As with genetic engineering, use of these techniques remains something not thought about. These eaters are not saying that pesticides do not denaturalize the food, but they think this sourcing method is a rational choice if compared to one which accepts processed products or ready-made dishes, which are described as the opposite of natural. The extract from the interview with Gaël

\footnotetext{
${ }^{8}$ For this type of respondent, there is not really any hierarchy in the type of alternative shop preferred; this is different from the consumers who eat only organic food and favor some shops more than others because they are more respectful of seasonality and maintaining short food chains.
} 
sums up this idea according to which natural food consists of the unrefined product and all that its preparation implies:

Gaël: [Natural food] it's rather the kind of thing where there are lots of peelings, there's work to do. That's what it is. The food isn't made to be eaten straight away. You have to wash it, peel it, cut it, you have to...that's it, there's work behind it. (Interview with Gaël, management level, Paris)

While food from organic sources or from integrated farming is more highly considered in the hierarchy of values, food from conventional supply chains (such as supermarkets) nevertheless remains natural in the minds of these eaters. In the context of processed foods such as animal by-products, it is noticeable that the nonmanufacturing link owes much to the image of these foods rather than to a search for information about the conditions under which they are produced.

Élisabeth: For me, cheese is natural, well, cheese is things that ferment. But I mustn't think about it too much because then I'm going to think about bacteria in cheese and I won't eat cheese any more [laughs]. But listen, I don't know. Cheese...Well, I see the... I don't see factories so, if you like, when I see cheese I don't see cheese factories. My image is more of cheeses that people make in little cheese dairies, you see, that kind of thing. (Interview with Élisabeth, extracurricular assistant, rural area)

The respondent made reference here to cheeses with a designation of origin (brie, Roquefort, camembert, etc.); despite this, they are not farmhouse cheeses but are manufactured by industrial processors (such as Lactalis). Just as for certain products that require a processing method considered traditional (wines, vegetable oils, jams, etc.), some stereotypical images of craft production help preserve the perception of the product as natural. It is not impossible that if these eaters were to be confronted with evidence of the actual production process, the association with the natural would be lost. Confirmation of this can be found in the changes in buying habits resulting from knowledge gained about manufacturing processes through the media.

Contrary to the views held by persons supporting the previous category, conventional retail outlets (like greengrocers and non-organic grocery stores or supermarkets) are not here perceived as purveyors of unnatural foods. What is important is to be able to make the right choice of product, particularly in supermarkets, which are considered spaces that sell all types of products, including good-quality ones. Weekly markets or shops specializing in organic food are perceived more as high-quality retail outlets but economically rather inaccessible. The survey therefore shows that the majority of people attributing these characteristics to natural food are those belonging to the middle classes and the gainfully employed working classes.

Natural food characterized by a "link loss" The natural food category in itself may have ceased to exist because of human activities, which, in our contemporary Western societies, have irreversibly denaturalized any consumable element. In this view, natural food is therefore perceived as a resource that is extinct. This might be thought, at first sight, to be a view held by individuals following special diets, such as advocates of the "paleo diet" who 
consider that the Neolithic age finally separated humans from what was "good" for their health (Vigne 2015). In fact, however, it concerns "ordinary eaters," who shop almost exclusively in mass distribution outlets (hypermarkets and distributors of the hard-discount type); and the purchasing habits of the large majority are directed towards agro-industrial products. Their discourse is marked by a very strong mistrust of production systems, whether these are conventional or alternative. From the chemical and synthetic processing used in agriculture to the introduction of undeclared elements (nanoparticles), even illegally (horsemeat in ready-made meals), to the use of bone meal, all these things reinforce the idea according to which "modernity" has eroded the health quality of food, which was better in the past. When questioned on points of detail about certain craft products, the discourse certainly becomes more nuanced, but the overriding idea about naturalness in relation to food is of a breach of trust towards the whole production system.

Alternative food channels, particularly those bearing the "organic farming" label, are not seen to offer an assurance of trustworthiness; on the contrary, they are subject to strong criticism on account of the cost represented by this sourcing method and the fact that it is impossible to guarantee the purity of products.

Francis: So, say you have two fields close to one another, not too far from one another. You can't tell me that at a distance of 100 or 200 metres, there are no residues that go from one to the other and, what's more, the ground water is the same. So they need to stop taking us for fools. (A pause.) Organic, for me, is just a way of making people pay a bit more, because it's more expensive. It's a rip-off. That's why organic is worthless as far as I'm concerned. (Francis, temporary manual worker, rural area)

This discourse of mistrust by Francis was indicative of others expressed by people who think that the link with nature has been broken. They were all members of the working classes, gainfully employed in some cases but in others lacking job security. After expressing criticism of the food industries, certain connections were made with the traditional dimension of food as part of the French heritage, as one respondent put it: "If pushed, you see, for me eating natural food is when you eat good things coming from the French countryside like boeuf bourguignon or blanquette de veau." This association between the emblematic dishes of a food culture thought of as traditional has already been highlighted by Claude Grignon with regard to certain social classes sharing common characteristics (1995).

Unlike the preceding categories of respondents, these people considered that food could be naturalized by virtue of what happened to it after it was bought. The cooking carried out in the home restored meaning to the very nature of what was eaten. In other words, when the ability to choose food was restricted by socio-economic factors, the boundaries of what was natural shifted towards the heritage aspect of food, which was supported by culinary culture and what this offers in terms of re-socializing food, if not restoring trust in it.

\section{Israeli classification of natural food seen through the lens of the "order of the edible"}

In Israel, the link between naturalness and food processing is present just as it is in France; and the image of an industry thought to denaturalize food is equally powerful. 
However, there is an important difference when one questions the ways in which naturalness is viewed. Although, for the French, it is human intervention that dominates in the three categories distinguished, in Israel it is automatically families of food (to adopt the typology of nutritional science) that establish the natural/unnatural dichotomy. When questioned about what would represent a natural food, Sarah immediately excludes any product of animal origin:

Sarah: I don't even think of meat. When I think of meat, I think of hormones, antibiotics, and large-scale production. That's what comes [to mind] when I think of meat and that's not natural at all. For me, that's what it's associated with. Same goes for fish. (Interview with Sarah, self-employed professional, Tel Aviv)

The reasons mentioned here directly reflect the question of product integrity and, consequently, the link with processing through human activity. In the course of our fieldwork, we noticed that nearly all our respondents classify vegetables and other nonanimal products as natural while meat products belong to the unnatural end of the spectrum. While, for the French, meat quite easily comes within the bounds of the natural, for the Israelis it is the opposite and it is usually respect for life that is mentioned as being the main reason for this categorization.

Anaelle: Natural food is really fruit and vegetables. Fruit and vegetables then, and after that lentils, all those sorts of things. I forget what you call those things.

\section{Interviewer: Legumes?}

Danielle: That's right, exactly. Like chickpeas! Hummus is completely natural. [...] If you eat natural food, you tend to eat less meat. There's also this idea of raw food in relation to cooked. Cooking is already a process. Meat is more often cooked. And then it's linked to a whole ethical system. Eating animals means killing animals so for me it's linked. Well, it is in my mind. You might say that animals are part of nature, but that's my idea. (Interview with Anaelle, management level, Tel Aviv)

Anaelle, who describes herself as a secular Jew, does not observe kashrut, the Jewish dietary laws; she eats many foods and food associations proscribed by these rules, such as seafood or eating dairy with meat. Nevertheless, there is a cultural base that supports this classification logic, which might be summarized as follows: in the beginning, humans were not made to consume meat. During the course of the interviews, many non-believers and non-practicing persons sometimes made reference to certain kashrut laws (ritual slaughter being presented as a means to limit animal suffering) or to early Biblical times (the Garden of Eden where meat was not consumed). These laws and beliefs, which our respondents interpreted in different ways, ${ }^{9}$ help structure the food culture of Israelis, whose logic for classifying natural foods is anchored in an order of what is edible (Douglas 1979). In this process, the exclusion of meat from the natural

\footnotetext{
${ }^{9}$ Some define kashrut as a set of rules motivated by sanitary concerns. Certain passages of the Torah may be thought of as parables offering a reading of the past and/or saying something about the human condition.
} 
category should not be confused with antispeciesism. Indeed, a very large majority of our respondents stated that they regularly ate meat, even if they wished to limit their intake; they also considered other products derived from animals, such as honey, as foods fit for human consumption.

Vegetables and legumes, by contrast, came well within the bounds of natural food. This was reinforced by the fact that they came from the souk, which was seen as a strong indicator of naturalness.

Françoise: For me, the souk has what is most natural. There are the aromas, the colours of all the produce and there's the atmosphere. Have you been there just before Shabbat? [...] That's where people go to buy everything they need to make a good holiday meal! (Interview with Françoise, senior executive, Jerusalem)

These people closely associate nature and culture, even though, unlike the case with some French eaters, what has come to be rooted in tradition subsequently is viewed as natural. The food bought in the souk harks back to the food of the past, firmly entrenched in tradition; so in the perceptions people have of food culture, there remains a timelessness that is the opposite of contemporary food, where everything is processed. That is why these kinds of markets are thought of as food sources that represent naturalness and, from this standpoint the ready-made dishes sold there are seen to be just as, if not more natural than raw types of food. Our survey shows that hummus bought in the souk is the product that comes up most spontaneously in discourse, when people are asked to name a comestible symbolizing natural food. Other dishes mentioned before fresh vegetables (and very rarely prepared at home) include tehina (or tahini: ground sesame-seed paste), zhug (a Yemeni sauce made from oil and hot peppers), and falafel (little balls made from ground chickpeas with spices and fried in oil). While according to our respondents these products are representative of Israeli food culture, the souk helps to construct this image of traditionally made dishes (which does not always accord with the reality) and reinforces the product's natural aspect, which is greater than if it were presented packaged in a supermarket.

This difference is less evident where vegetables are concerned. The souk enables people to save money but, from the eaters' point of view, it offers no different guarantee as to provenance or farming method. In fact, these latter aspects were of no or little concern to the Israelis we met. For a European, it can be surprising to see that there is no indication of provenance for vegetables sold in the market or in conventional shops. When asked if that posed a problem for them, the responses were similar to those of Mickael:

Mickael: Everything comes from Israel so, no, we don't need it to be labelled, we know it. It's a small country compared to France. There aren't all the problems that you have, the scandals and all that. We don't ask ourselves the question. They are good products! (Interview with Mickael, management level, Tel Aviv)

\footnotetext{
${ }^{0}$ Some define kashrut as a set of rules motivated by sanitary concerns. Certain passages of the Torah may be thought of as parables offering a reading of the past and/or saying something about the human condition.
} 
However, the interviews carried out with those running supermarkets indicate that although a substantial portion of fruit and vegetables come from Israel, there are also imported products on the market. Eaters' perceptions are that everything comes from their own country out of respect for seasonality. People are not particularly worried about the type of farming used in producing vegetables and legumes, unlike the French respondents belonging to the same social class.

The fact that vegetables are at the top of the hierarchy for naturalness is connected above all to the place where they are sold-the souk being without parallel-rather than to the manufacturing process. In this conception of naturalness, product segments carrying the organic label are perceived as an unduly expensive niche market designed for consumers who are very, or even overly worried about their health. As for availability, we noted that organic products were mainly on offer in specialized shops in alternative networks and especially present in large cities like Tel Aviv or Jerusalem. Supermarkets, on the other hand, offered no range of foods for this preference (although this observation was made in 2014 and it is possible that the range of organic food on offer has changed since then).

In Israel's urban areas, the food market in which "ordinary eaters" can obtain supplies therefore appears to be divided in two: on one side are conventional shops which are favored for buying everyday food and, on the other, the souk, which is considered the most appropriate place for shopping for Shabbat and Jewish holidays. Although the quality and/or price of products may be one of the reasons for this choice, at least if not more important is the souk's social dimension. On Friday evenings or on the days before Jewish holidays, these markets are very busy places of commerce-in the etymological sense-where different purchases are accompanied by discussions between shoppers and sellers and interspersed with numerous good wishes for Shabbat (Shabbat Shalom) or for the coming feast days. The fact that this shopping location is presented as the place where natural foods are to be found shows that the conception of this food category is closely related to everything that is cultural.

\section{Conclusion}

The constants characterizing the perceptions of natural food from the consumers' point of view betoken a form of generalized mistrust towards certain industrial manufacturing processes and/or farming techniques. Over and above this breach of trust, which is common to both countries studied, many variations appear in what constitutes the focus of mistrust where the food production channels are concerned. A whole body of knowledge, but also of stereotypical images (positive as well as negative) about techniques and production systems, contribute to defining the boundary which makes the industrial process disparaged. To this may be added the interpretations of what is accepted or tolerated as possible ways of using nature without going against it. Perceptions of natural food are built up through what is opposed to them, but this is not the only factor. The elements supporting the logic by which these eaters make their classification are different from those having personal dietary regimens. The roots are to be found in their food culture as well as in the space for 
choice as regards available food-sourcing channels. This shows the advantage of pursuing research in the sociology of food that does not compartmentalize means of production on the one hand and consumer practices on the other, but rather reconnects the two (Goodman 2002, 2003).

In France and Israel, therefore, perceptions of natural food differ and are both socially and culturally embedded. The way in which eaters conceive of naturalness does not appear to be a reflection of their food-sourcing methods but offers a reading of their practices through a particular lens. More specifically, it can provide some understanding about what reinforces choices and how justifications are developed when room for decision is seriously reduced because of economic and social constraints. Those who, in France, have a perception of natural food characterized by the non-intervention link are either intermittent organic eaters or occasional consumers of this type of food. Most of their food continues nevertheless to be purchased from conventional outlets because diversification requires time. This same logic can be seen in the food-sourcing methods of Israelis from similar social backgrounds. Strongly symbolic of natural food, the souk is a place for buying food mostly used when time is not at a premium, very often on Fridays (corresponding to Saturdays in France) when people are not working and invite friends or family for Shabbat or other festive meals. Although these consumers say they mistrust certain food industries, the prospect of a possible choice in their means of provisioning maintains a bond of confidence in what they eat.

With respondents for whom the perception of natural food is characterized by the loss of any link, their discourse highlights a particularly severe limitation in their shopping methods. For these respondents, belonging to working-class strands of society (gainfully employed or in unstable situations), limitations are economic insofar as alternative food-provisioning channels instantly appear totally unacceptable, since they are perceived as outrageously expensive; but this constraint is also social because the challenge of incorporating normative guidelines to follow a diet to prevent weight gain and, more generally, to eat healthy foods, encounters resistance from the eating habits entrenched in family cultures (Régnier and Masullo 2009; Mathiot 2014; Plessz et al. 2014). Faced with too great a disparity between the range of provisioning practices seen as limited and the positive image of natural food promoted by alternative food industries - which appears inaccessible and the province of more privileged social groups-discourses tend towards a form of resignation with regard to the "risky consumption" (Giddens 1998) induced by their buying methods. This resignation can be seen in a general mistrust of the whole system of food production, but also in a discourse of reaction to natural food. This type of food is presented as a value belonging to the past which, in the perceived images, is partly idealized in certain cases. Since the space for decisions about buying is restricted, natural characteristics are reaffirmed after the event, through cooking. Construction of a French food heritage expressed by dishes formerly symbolizing a regional identity means that sauerkraut, cassoulet, or boeuf bourguignon become emblematic of what is natural. As far as food is concerned, the nature/culture relationship in contemporary Western societies remains inextricable. 


\section{References}

Adamiec C. (2016) Devenir sain. Des morales alimentaires aux écologies de soi. Tours/Rennes: Presses Universitaires François Rabelais/Presses Universitaires de Rennes.

Arnould, P., \& Glon, E. (2006). Wilderness, usages et perceptions de la nature en Amérique du Nord. Annales de géographie, 649(3), 227-238.

César C. (1999) De la conception du "naturel”, Les catégories de l'entendement à l'oeuvre chez les consommateurs de produits biologiques: contribution à une socio-anthropologie de l'alimentation. Nanterre: Thèse de doctorat de l'Université Paris X-Nanterre.

Coveney, J. (2006). Food, morals and meaning: The pleasure and anxiety of eating. London: Routledge.

de Verdalle, et al. (2012). S'inscrire dans une démarche comparative. Enjeux et controverses, Terrains \& travaux, 21, 5-21.

Détienne, M. (2000). Comparer l'incomparable. Paris: Le Seuil.

Dogan, M., \& Pélassy, D. (1982). Sociologie politique comparative: problèmes et perspectives. Paris: Economica.

Douglas, M. (1966). Purity and danger, an analysis of concepts of pollution and taboo. London: Routledge.

Douglas, M. (1979). Les structures du culinaire. Communications, 31, 145-170.

Dubuisson-Quellier, S. (2013). Ethical consumption. Halifax: Fernwood Publishing.

Fischer, C. (Ed.). (1994). Manger magique, aliments sorciers, croyances comestibles. Paris: Autrement.

Fischler, C. (1990). L'homnivore. Paris: Odile Jacob.

Fischler, C. (2015). Is sharing meals a thing of the past. In C. Fischler (Ed.), Selective Eating: The Rise, Meaning and Sense of Personal Dietary Requirements [trans. Cynthia Schoch \& William Snow] (pp. 1535). Paris: Odile Jacob.

Giddens, A. (1998). The risk society: the context of British politics. In J. Franklin (Ed.), The politics of risk society (pp. 9-34). Cambridge: Polity.

Goodman, D. (2002). Rethinking food production consumption: integrative perspectives. Sociologia Ruralis, 42(4), 271-277.

Goodman, D. (2003). The quality "turn" and alternative food practices: reflections and agenda. Journal of Rural Studies, 19(1), 1-7.

Grignon, C. (1995). L'alimentation populaire et la question du naturel. In N. Eizner (Ed.), Voyage en alimentation (pp. 63-78). Paris: ARF Editions.

Grignon, C., \& Grignon, C. (1981). Alimentation et stratification sociale. Cahier de nutrition et diététique, 16(4), 207-217.

Harris, M. (1985). Good to eat, riddles of food and culture. New York: Simon \& Schuster.

Lamine, C. (2007). Les intermittents du bio. Editions MSH/Quae: Paris/Versaille.

Lepiller O. (2010) Chasser le naturel: l'évolution de la notion de naturalité dans l'alimentation à travers les livres français de diététique "naturelle" depuis 1945. In Bruegel M., Nicoud M., Barlösius E. (Eds.), Le choix des aliments: informations et pratiques alimentaires de la fin du Moyen Âge à nos jours, (pp. 97119). Tours/Rennes: Presses Universitaires François Rabelais/Presses Universitaires de Rennes.

Lepiller O. (2012a) Critiques de l'alimentation industrielle et valorisations du naturel: sociologie historiqued'une "digestion" difficile (1968-2010). Toulouse: Thèse de doctorat de l'Université de Toulouse 2 Le Mirail.

Lepiller, O. (2012b). Naturel. In J.-P. Poulain (Ed.), Dictionnaire des cultures alimentaires (pp. 905-911). Paris: PUF. Lepiller, O. (2016). Valoriser le naturel dans l'alimentation. Cahiers de Nutrition et de Diététique, 51, 73-80.

Mathiot, L. (2014). L'alimentation des enfants du point de vue de leurs parents: des représentations du risque différentiées selon l'appartenance sociale des familles. Sociologie et sociétés, 46(2), 133-154.

Ossipow, L. (1997) La cuisine du corps et de l'âme. Neuchâtel/Paris: Editions de l'Institut d'Ethnologie de Neuchâtel/Editions de la MSH.

Ouédraogo, A. (1998). Manger "naturel": les consommateurs de produits biologiques. Le Journal des Anthropologues, 74, 13-27.

Plessz, M., Dubuisson-Quellier, S., Gojard, S., \& Barrey, S. (2014). How consumption prescriptions affect food practices: assessing the roles of household resources and life-course events. Journal of Consumer Culture, 16(1), 101-123.

Poulain, J.-P. (2002). Sociologies de l'alimentation. Paris: PUF.

Régnier, F., \& Masullo, A. (2009). Obésité, goûts et consommation, Intégration des normes d'alimentation et appartenance sociale. Revue Française de Sociologie, 50(4), 747-773.

Roininen, K., Arvola, A., \& Lahteenmaki, L. (2006). Exploring consumers' perceptions of local food with two different qualitative techniques: laddering and word association. Food Quality and Preferences, 17(1-2), $20-30$. 
Rozin, P. (2008). La préférence pour le naturel. In C. Fischler \& E. Masson (Eds.), Manger, Français, Européens et Américains face à l'alimentation (pp. 193-208). Paris: Odile Jacob.

Vialles, N. (2007). Des invariants du régime carnée. In J.-P. Poulain (Ed.), L'homme, le mangeur, l'animal, Qui nourrit l'autre? (pp. 197-106). Paris: Les Cahiers de l'Ocha.

Vigne, J.-D. (2015). The 'prehistoric diet', myths and scientific realities. In C. Fischler (Ed.), Selective eating (pp. 92-119). Paris: Odile Jacob.

Wier, M., Hansen, L. G., Andersen, L. M., \& Millock, K. (2003). Consumer preferences for organic foods. In OECD (Ed.), Organic agriculture: Sustainabiblity, markets and policies (pp. 257-271). Wallingford: CABI Publishing.

\section{Translated by Cynthia Schoch and Rosemary Rodwell}

